\title{
Learning in a Small, Task-Oriented, Connectivist MOOC: Pedagogical Issues and Implications for Higher Education
}
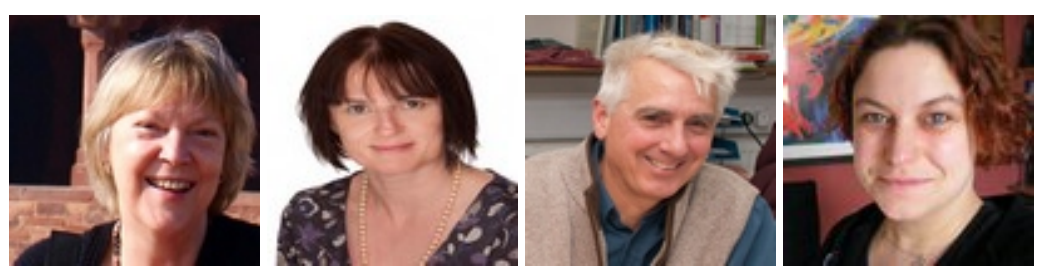

Jenny Mackness ${ }^{1}$, Marion Waite ${ }^{2}$, George Roberts², and Elizabeth Lovegrove ${ }^{2}$ ${ }^{1}$ Independent Education Consultant, UK, ${ }^{2}$ Oxford Brookes University, UK

\section{Abstract}

Despite the increase in massive open online courses (MOOCs), evidence about the pedagogy of learning in MOOCs remains limited. This paper reports on an investigation into the pedagogy in one MOOC - Oxford Brookes University's 'First Steps in Learning and Teaching in Higher Education' MOOC (FSLT12).

FSLT12 was an open and free professional development opportunity for people moving into HE teaching. It was a small course (200 participants registered from 24 countries) which was focused on introducing $\mathrm{HE}$ teaching skills, and, uniquely, to deliberately integrate open academic practice as a vital part of professional development for HE teachers. A qualitative, case-study approach was used in the research, based on surveys, interviews, and social media, to provide evidence about how people learned in this course and consider wider implications for teaching and learning in higher education.

The evidence shows that participants who completed the course were able to learn autonomously and navigate the distributed platforms and environments. The most challenging issues were acceptance of open academic practice and difficulty in establishing an academic identity in an unpredictable virtual environment. An interesting and significant feature of the course was the support for learners from a number of MOOC 'veterans' who served as role models and guides for less experienced MOOClearners.

The research shows that small task-oriented MOOCs can effectively support professional development of open academic practice.

Keywords: MOOCs; FSLT12; open academic practice; higher education; case study 


\section{Introduction}

2012 saw many types of MOOCs offered openly and 'for free' by a variety of higher education institutions around the world. It was also the year in which the Oxford Centre for Staff and Learning Development (OCSLD) at Oxford Brookes University ran one of the UK's first MOOCs: First Steps in Learning and Teaching in Higher Education (FSLT12).

One of the aims of FSLT12 was to trial and evaluate a MOOC for open, autonomous, and interactive professional development. How people experienced this in FSLT12 was investigated through an analysis of participant engagement with

- connectivist MOOC (cMOOC) learning principles (autonomy, diversity, openness, and connectivity);

- $\quad$ cMOOC activities (aggregate, remix, repurpose, feed forward); and

- cMOOC behaviours (consumer, producer, learning from and with others, mentoring/ teaching others, active observation).

cMOOCs are based on a philosophy of connectivism and networking' (Daniel, 2012) and 'are defined by a participative pedagogical model' (Siemens, 2012a).

Distributed platforms, autonomy, diversity, openness, and connectivity were identified by Downes and Siemens (conveners of the first cMOOC in 2008, CCK08) to be key principles for learning in networks (Downes, 2009a, 2013). Downes and Siemens have described four key MOOC activities: aggregation (filtering, selecting, and gathering personally meaningful information); remixing (interpreting the aggregated information and bringing to it personal perspectives and insights); repurposing (refashioning the information to suit personal purposes); and feeding forward (sharing the newly fashioned information with and learning from other participants) (Kop \& Carroll, 2011). Typical MOOC behaviours were researched by Kop (2011). These principles and activities formed part of the basis for the design of the FSLT12 MOOC, and the research questions which provide a focus for this paper are:

- How did cMOOC design principles and activities in FSLT12 enable participant learning?

- What are the deeper implications for learning of the principles and activities used in the design of FSLT12?

- What are the possible implications of small task-oriented cMOOCs for higher education? 


\section{Background to the FSLT12 MOOC Development}

A MOOC is a complex phenomenon leaving aspiring designers and conveners with many questions and decisions to make. The key question to answer is one of underlying pedagogy, which will inevitably affect the learning experience and learning itself (Sloep, 2012).

Mackness, Mak, and Williams (2010), following their experience of CCK08, had reservations about whether the process of translating Downes' four key principles (autonomy, diversity, openness, and interactivity/connectedness ) into the reality of student experience was that straightforward. And Tschofen and Mackness (2012) showed that these characteristics are more complex to understand in relation to individual identity and experience than might first be realized.

The introduction of monstrously massive MOOCs or 'xMOOCs' (Downes, 2013a), such as edX and Coursera, which have attracted up to 150,000 participants, has further complicated the understanding of MOOCs. They have also increased the 'for or against' debate, in terms of whether or not people can learn effectively in MOOCs (Rees, 2013), and, in particular, in xMOOCs, which are viewed by Boxall (2012) as the online version of traditional instructivist correspondence courses, as opposed to cMOOCs which emphasize 'creation, creativity, autonomy and social networked learning' (Siemens, 2012b).

There are now many 'hybrid' MOOCs too (Roberts et al., 2013, Conole; 2013, Clark, 2013), including small MOOCs. Downes (2013b) suggests that for an open course to qualify as a MOOC, it must be 'massive' and that 'massive' refers to an open course where the active participants number more than Dunbar's number (c. 150). Lisa Lane (2012) suggests that MOOCs can be grouped into three types: network-, task- and content-based. FSLT12 had 206 registered participants and was designed as a small task-based MOOC.

\section{Design for Learning in FSLT12}

The pedagogical design of the FSLT12 MOOC was determined both by the perceived learning needs of the intended audience and by the need to align it with an established face-to-face course. Alignment was necessary in order to test whether the MOOC could be offered for credit in 2013. In 2012, it was run as a pilot with the award of a certificate of achievement only. Ultimately this certificate went to 14 participants (out of 60 consistently active participants) who opted for their completed tasks to be assessed by the MOOC conveners. They also received feedback from their peers. The FSLT12 MOOC was targeted at new lecturers, PhD students who teach, and people moving into HE from industry. It attracted participants new to $\mathrm{HE}$ and learning online, as well as MOOC 'veterans' and experienced lecturers (Waite et al., 2013). The six week course (Figure 1) was resource-based and task-oriented and aimed to develop and 
extend knowledge, skills, and understanding of learning and teaching in higher education (Waite et al., 2013).

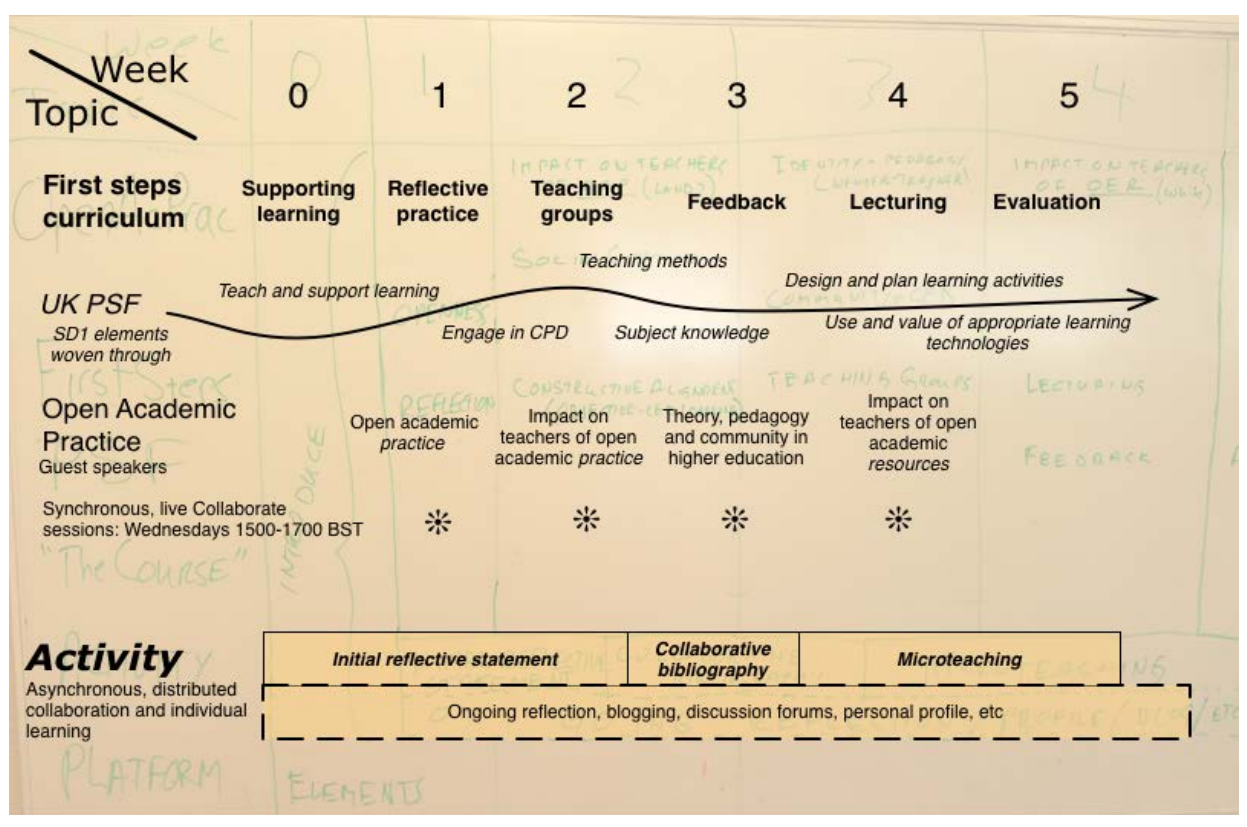

Figure 1: FSLT12 MOOC schedule.

Given that the MOOC was targeted at new HE lecturers, this MOOC intentionally created a more supportive learning environment than is encountered in some traditional cMOOCs such as ChangeMOOC. Not only were 'veterans' encouraged to support participants new to MOOCs and lecturing in HE, but the three tutors and three technologists also had a greater 'presence' than is customary in some traditional cMOOCs, providing individual and whole group support, particularly for those participants being assessed, and by monitoring discussions and providing feedback on completed tasks.

Of the 206 registered participants from 24 different countries 60 were active in the Moodle discussion forums throughout the 6 weeks that the course ran. Participants were encouraged to work across distributed sites and platforms of their choosing (Waite et al., 2013). A distributed environment is an essential element of cMOOCs in supporting autonomy, connectivity, and interaction (Daniels, 2012; Downes, 2009b). The course used Wordpress, Moodle, and Blackboard Collaborate platforms and participants' blogs were aggregated into the Wordpress site. Twitter was also used extensively: 832 tweets posted by 114 participants.

Each of the 5 weeks featured an editable collection of prepared resources, a series of discussion boards, and a live online session with a guest speaker. The last synchronous sessions of the course featured the course participants showcasing their 10-minute-long microteaching activities, sharing their practice, and offering each other feedback. 
Integral to the course design was the expectation that knowledge would be co-created through active, autonomous participation and that learning would 'emerge' through the interactions around the key activities of aggregation, remixing, repurposing, and feeding forward. In the process, open academic practice (across 'teachers' and learners') becomes the overarching core (cMOOC) activity, and the four key activities (above) become mechanisms to achieve this.

\section{Research Methodology and Data Collection in FSLT12}

A qualitative, case-study approach was taken to the research and data. The University Research Ethics Committee granted approval and participants were informed about the authors' research intentions at the start of the MOOC. Data were collected through the use of surveys, focus groups, and semi-structured face-to-face and email interviews. Discussion forums, participant blogs, and a Twitter archive were also analysed for evidence of how participants learned.

Table 1

Data collection in FSLT12

\begin{tabular}{|l|l|}
\hline Type of data collection & Questions focused on \\
\hline Survey & $\begin{array}{l}\text { Patterns and levels of participation in } \\
\text { FSLT12 activities and online sites }\end{array}$ \\
\hline Focus groups & $\begin{array}{l}\text { Organisation of the FSLT12 MOOC, } \\
\text { assessment, use of technology/ activities, } \\
\text { inclusive practice }\end{array}$ \\
\hline $\begin{array}{l}\text { One-to-one interviews with assessed } \\
\text { participants }\end{array}$ & As above \\
\hline Email interviews & $\begin{array}{l}\text { The way participants learn in cMOOCs } \\
\text { related to principles, activities and } \\
\text { behaviours }\end{array}$ \\
\hline
\end{tabular}

This mixed method approach allowed for triangulation of the data and gave rigor to the case study (Waite et al., 2013).

Data were collected immediately following the end of the MOOC using an online evaluation questionnaire targeted at all participants $(N=21 / 206)$. At the time, 60 participants were active in the forums so 21 responses represents a $34 \%$ response rate. Two online synchronous focus groups were held within the Blackboard Collaborate environment. Face-to-face and Blackboard Collaborate semi-structured individual interviews were held for a targeted group of assessed participants $(n=4 / 14)$. Blog, Twitter, and Moodle discussion forum analysis was undertaken. 
In most MOOCs the majority of participants (typically $80-90 \%$, but 70\% in FSLT12) are not visibly active and may be observing, reading, listening, or engaging in other ways (Rodriguez, 2012). Nevertheless, it is important to try and capture the voice of these participants if we are to fully understand how and what people learn in MOOCs. A further survey, with specific questions about modes of and reasons for different levels of participation, was therefore sent out by email to all registered participants $(\mathrm{N}=27 / 206)$ and this was followed up with email interviews of those participants who agreed to this $(\mathrm{n}=7)$.

\section{Learning in FSLT12}

The data were analysed from the perspective of MOOC learning principles, MOOC activities, and MOOC behaviours.

\section{Autonomous Learning across Distributed Platforms}

Working across distributed platforms allows learners considerable autonomy, but also requires the associated technical, navigation, and critical thinking skills. Learners new to MOOCs may find working across distributed platforms difficult and disorienting; experienced 'MOOCers' expect this (Waite et al., 2013).

Learners who were most successful fell into three groups: those who recognized the time commitment needed to learn new skills: 'There's a period of time which you have to devote to navigation' (interview); those who were being assessed and were motivated through this commitment: Having an assessment piece really added value for me in terms of motivation and commitment' (first survey); or those who already had a personal enthusiasm for working autonomously.

One of the course conveners suggested that The development of autonomy benefits from scaffolding' (blog post), and a participant suggested inviting mentors to support novice 'MOOCers'. This suggestion was adopted for the next run of FSLT in 2013.

Although fostering autonomy was thought to be an essential part of the learning process and design, the constraints on autonomy were also recognized:

Realistically, however, in the "real world" we do have deadlines, and we do have specific deliverables; so in essence we have a roadmap and constraints. (discussion forum) 


\section{Learning through Diversity}

The diversity of participants was both valued and experienced as challenging:

It was great to meet people from all over the world and share with all of them. (interview)

$$
\text { [but ...] }
$$

The mix of novices and experts is interesting. Fast pace of synchronous sessions and technology might exclude novices. There is also a culture to learn. (focus group)

A spontaneous discussion in one of the early discussion forums around a video posted by a participant (Higher Education and Social J ustice - J ennifer Simpson) highlighted the importance of educating to 'deal with difference', but one participant noted that:

Diversity diminishes during the course - posts drop off and ends up with a core group. (interview)

However, the high number of people who were just temporarily 'sampling' the course ('drop-outs', Watters, 2012), or actively observing ('lurkers') are legitimate parts of the diversity of the participant mix in open MOOCs. This makes the analysis of diversity, and sustaining diversity in MOOCs much more complex.

\section{Learning Through Openness and Interactivity}

Openness in FSLT12, in the sense of open sharing, featured in the content (a focus on open academic practice and open educational resources), discussion, and reflections of participants:

One of the things about open academic practice... is "lifting the lid" on the reality of our work. (discussion forum)

In her live presentation to FSLT12 MOOC participants, Frances Bell said:

I prefer to think of openness as a default option that can be turned off, not as a zealot's precept,

and in a related blog comment wrote:

The challenge for 21st Century educators and learners is that they operate in a mixed public/ private arena where ideas may be exchanged in a quasi-private arena but shared or fed to more public arenas. 
Openness was seen as important to the future of higher education, but also difficult to achieve, particularly in relation to assessment.

By taking part in open initiatives any way -- as an instructor, course designer, student, blogger, drive-by commentator, or even just an interviewee for a research project -- we are part of the collaborative effort to imagine, create, test, and improve the future of higher education for teachers, students, and society at large. (follow up evaluation)

It's probably quite difficult to give honest, critical feedback on microteaching without hurting people's feelings, especially when relationship is entirely virtual? ... I'm guessing tendency is to go softly, to err on the side of not crushing people's efforts. (focus group)

Interactivity between FSLT12 participants was supported for many by the live synchronous online webinars: They make me feel more connected to real people'; There is no substitute for actually talking with people' (follow up evaluation). Hearing people's voices, engaging in the 'chat', connecting with others to ask for help, social conversations, and, for four participants, a face-to-face meeting were all thought to contribute to connectivity. One participant asked in a discussion forum 'So is learning all about the connections we make?'

For others, lurking and limited openness were seen as important options.

This (active lurking) was probably my most dominant behaviour due to time commitments. I was mainly in the background, watching with interest, thinking and pondering... But I am glad I had the chance to even lurk, to see the organization of the event and consider how this could be used in my own practice... To be honest I think that many will lurk in these events, but that doesn't mean they are not valuable learning experiences... It was legitimate and peripheral and I was part of the community and when I could attend the live event I joined in the dialogue. I guess the issue for organizers is how much resource can you put in to something where majority may lurk - how can you appease funders that this is a worthy and valuable activity. Because it is/ was. (email interview) 


\section{Organising Learning Through Aggregation}

Aggregation was an integral element of the FSLT12 design. Participant blogs were aggregated into the Wordpress site and wikis were designed into each of the week's content for the aggregation of open educational resources and participants' completed tasks.

Participants also aggregated their own resources through a Twitter archive, a Google map, a personal wiki, a personal blog roll, Word documents and folders, use of Google Reader, Diigo, bookmarking, and the creation of a list of useful links. Many of these aggregated resources were openly shared. As one participant wrote on her blog about the Twitter archive she created:

The archive enables us to revisit comments and links shared via Twitter at any point and essentially it becomes part of our memory... At a later stage it could provide some meaningful data on: the virtual connections participants made; the kind of links we shared; what kind of information we shared.

Another participant valued blogging for aggregation, 'Blogging integrates everything to me' (follow up evaluation) and blogs were also seen by one commenter as preferable to discussion forums for being searchable:

I would not have seen this question (or other stuff you have written in the interim) if it had been locked away in a discussion forum. So I hope you continue blogging. (comment on a participant blog)

\section{Co-Creation and Creativity through Remixing and Repurposing}

As would be expected in a MOOC focusing on teaching and learning in Higher Education, many academic references were posted and one of the assessment tasks required the co-creation of an annotated bibliography. The question was raised on one participant blog as to whether we now have a copy and paste culture and whether remixing equates to plagiarism.

There was also evidence in FSLT12, but less so, of repurposing resources. This was promoted in particular by the final microteaching activity, which was completed by those being assessed, but also by some non-assessed participants. Some participants repurposed their own past work to fit the assessment requirements, but others created their presentations from scratch. One participant explained her repurposing as follows:

For my FSLT12 microteaching, I'd like to share a mashup that includes Luis Moll's Funds of Knowledge, Jim 
Cummins's and Dennis Sayers's collaborative critical inquiry, blogging, VoiceThread, and Second Life. Inspired by my other summer MOOC, Digital Storytelling 106, I've created a video to share the story of this pedagogical pattern that I've tested multiple times in my online teaching of ECI 521, Teaching Literature for Young Adults. (participant blog)

\section{Coping with Uncertainty and Identity Building}

Connectivist MOOCs may be pedagogically disruptive (Downes, 2013c) and this can have a significant impact on participant learning experiences and sense of personal identity. As one participant put it:

A MOOC allows me to play with uncertainty and depending on how my day is going, that can be scary or liberating. (discussion forum)

Another participant wrote:

This is my 4th or 5th MOOC and I have yet to work out what the damn thing is "for" or even why exactly I'm here. As a description I'd say this is a place where the challenge of the unexpected happens in an environment populated with thoughtful people (pleasurable place to be) and the path I follow to understanding is mine to decide. Funny, but all my life I've heard "don't worry, someday it will all come together" when something was beyond my understanding and not worth hammering into my thick head at the time. As I get older, that statement feels less like a declaration that understanding will emerge from following the exact steps that lost me in the first place and more like a prediction that somehow sense can be made - even if path to it only makes sense to me. A MOOC is education that comes to me to be processed as I choose. Were it strictly defined as a "course" this approach would likely lead me well away from the understanding the outcomes promised me in the catalogue. (discussion forum)

And yet another:

I think dealing with uncertainty AND dealing with criticism are good requirements for both academics and non-academics alike. (discussion forum) 
All three of these comments were made by experienced 'MOOCers'. Participants new to MOOCs prefer a more linear, structured environment, with 'plain language, numbers or map of something'. As one participant expressed it:

A good MOOC creates 'safe space' to experiment, risk, trust, fail, try again. ...There is something massive here about how less structured, less controlled perspective on MOOCs will feel uncomfortable for learners used to being spoonfed/guided. Huge shift, we can't underestimate the level of discomfort associated. (focus group)

Some participants recognized the effect that a MOOC environment could have on their identity and how identity might change over time in unexpected ways:

It changed my learner identities from confidence and experienced to not having a clue and feeling like a novice. (focus group)

Another participant recognized the relationship between working in different online environments and identity:

We sit in multiple places at once. Each tab on the browser represents a different aspect of oneself interacting with others. In any one day we sit as broadcasters, friends, intimates, eavesdroppers and audience, oftentimes switching between modes of beingwith within seconds. (focus group)

\section{Emerging Pedagogical Issues}

The data analysis revealed four significant pedagogical issues for learning in FSLT12.

\section{Learning across distributed platforms}

Learning in cMOOCs usually takes place over distributed platforms. The premise of a cMOOC is that in an age of plentiful and open information, learners cannot hope to commit this information to memory and must instead build and maintain a network of connections for easy reference (Siemens, 2004). Downes (2009) posits that knowledge is in the network. Learners must develop the skills of finding relevant information, critical analysis, synthesis, and meaning making. They need to become adept at filtering and selecting from the wealth of information that is available and to develop high levels of critical capability (Kop \& Bouchard, 2011).

We found that many learners find the abundance of information now accessible through the internet overwhelming. Despite this, active learners can, with support, develop 
appropriate technical skills to be able to engage with online content. They can become producers of multi-media content, aggregating, remixing, and repurposing resources they find through their online connections. They also gain the confidence to attend and contribute to live synchronous sessions, to openly share their work and ideas, and to cooperate and/ or collaborate in social networking environments. They shift from being consumers to producers (Kop \& Carroll, 2011). Technical skills are important but Anderson (2009) stresses the importance of pedagogy. With a balance between technology and pedagogy, learning can flourish, through interaction and collaboration (Kop \& Carroll, 2011).

\section{Social construction of knowledge}

Active participants in FSLT12 understood that social construction of knowledge is a key element of MOOCs. Learning in MOOCs is less reliant on the teacher and depends to a large extent on the connections that people make, both to the content and to each other, and on the negotiation of meaning. In FSLT12 the 'veteran' MOOCers provided significant support for those new to learning in MOOCs (Waite et al., 2013).

The idea that learners negotiate meaning through social interaction is not new. Seely Brown (2008) in discussing the impact of the internet on learning writes:

... our understanding of content is socially constructed through conversations about that content and grounded interactions, especially with others, around problems or actions. The focus is not much on what we are learning but on how we are learning.

Wenger has also discussed this in depth in relation to his social theory of learning (1998). For Wenger the term 'negotiation' conveys 'a flavour of continuous interaction, of gradual achievement, and of give-and-take' (1998, p. 53). More recently Wenger's work has focused on learning citizenship (2009) which means that as citizens, learners must know how to engage in social learning spaces, know when to disengage from a learning space and move on, know how to work across boundaries and between spaces, and know how to convene a community of practice.

However, Anderson and Dron (2011) point out that learning in connectivist space is, paradoxically, plagued by lack of connection' and that learners can be lost in social space' (Dron \& Anderson, 2009). The ability to make connections and negotiate learning cannot be assumed by learners, teachers, or course designers. Learners need to be self-motivated and self-directed (Kop \& Fournier, 2011).

\section{Open academic practice and building an identity}

Connective practices also have profound implications for open academic practice and identity, which several participants in FSLT12 recognised. 
Martin Weller (2011) sees openness as a 'state of mind' and necessary for scholarly practice, but as Burton (2009) points out:

a typical scholar is very exclusive, available only to students in specific academic programs or through tollaccess scholarly publications that are essentially unavailable to all but the most privileged.

Burton believes that the Open Scholar is someone who makes their intellectual projects and processes digitally visible'. This has significant implications for academic research and publication, but also, more importantly, for academic identity.

Barnett (2007) writes that:

'Being' has to be claimed as a key concept in any serious reflection on higher education, especially any thinking concerned with students and their experience. It is through her being that the student comes into a relationship or, rather, a set of relationships with all that she encounters.

According to Wenger (1998) learning, meaning, and identity are inextricably intertwined and Building an identity consists of negotiating the meanings of our experience' (p. 145). But meaning making and identity formation across distributed networks and in an age of information abundance, complexity, and uncertainty means that today's learner has 'a tough time of it' (Barnett, 2007, p. 36). These days we have to manage multiple trajectories all at once. It’s hard work (Wenger, 2011).

Mastery of learning requires understanding the struggle of what it takes to become something. (Wenger, personal communication, 2012)

\section{Embracing uncertainty}

Nowhere is this struggle more apparent than in connectivist learning environments. To be successful, learners in a cMOOC need to embrace this uncertainty (Cormier, 2012). There will be times for teachers/facilitators/ MOOC conveners and learners when levels of uncertainty, risk, and unpredictability are so high as to make the learning experience feel 'scary' and unsafe. However, as learners become more familiar with working in less structured, open, diverse, and connected environments, learning is more likely to be experienced as 'sweet' emergence (Williams, Mackness, \& Gumtau, 2012).

FSLT12 MOOC exposed learners to many of these new ways of learning. They worked across distributed platforms, aggregating, remixing, repurposing, and openly sharing resources. They were exposed to an uncertain and unpredictable environment, in which it was expected that learning and to some extent the curriculum itself would be 
emergent (Williams, Mackness, \& Gumtau, 2012). As the course progressed and with the support of tutors and experienced 'MOOCers', participants became more accepting of uncertainty and increased in confidence as open academic practitioners.

\section{Conclusions and Implications for Higher Education}

Whilst the findings of this research cannot be generalised due to the small sample size, it is possible to draw some tentative conclusions, which might have implications for academic practice in higher education.

\section{How FSLT12 Design Principles and Activities Enabled Participant Learning}

Participants who remained active throughout FSLT12 were those who were, or who learned to be, autonomous, open, connected, and interactive. They also demonstrated the technical skills required to navigate across distributed environments, filter, select, and aggregate the resources, and remix, repurpose, and feed forward artefacts and learning.

The diversity of the participant group and, in particular, the participation of 'veteran MOOCers' was significant in supporting those who were new to a MOOC (Waite et al., 2013). However, as one participant said: 'Diversity diminishes during the course - posts drop off and ends up with a core group' (interview). This suggests that whilst MOOCs such as FSLT12 might start, even with the support of 'veteran MOOCers', close to the edge of chaos, they become by the end of the course more like a community of practice.

\section{The Deeper Implications for Learning of the Principles and. Activities Used in the Design of FSLT12}

Most challenging for all participants, whether experienced or inexperienced 'MOOCers', were issues around coping with uncertainty, openness, and academic identity. MOOCs have been described by Yuan and Powell (2013) as intimidating, complex, and confusing. For academics and researchers, particularly those new in post who are learning to teach and trying to establish a reputation, openness can be a risk. FSLT12 tasks required participants to work, learn, and teach in an open environment.

The consistent, active engagement of a number of MOOC 'veterans' and the fact that this was a small, task-oriented MOOC were important in supporting FSLT12 participants to cope with uncertainty and to develop as open academic practitioners. 


\section{The Possible Implications of Small Task-Oriented cMOOCs for Higher Education}

The evidence from FSLT12 suggests that there are learning gains to be had from opening a course, particularly if it attracts veteran 'MOOCers', who support the teaching/ facilitation process. In challenging traditional ways of thinking and working in higher education, cMOOCs have the potential to improve teaching and encourage innovation and new pedagogical practices (Yuan \& Powell, 2013).

FSLT12 was offered free to the world, but required new online platforms to be designed and a team of six to plan and run the MOOC. It was run as a pilot and was financially viable because it received funding from the JISC/HEA, but this funding did not continue for the second run of the MOOC in 2013. Despite this, for 2013 the course was formally accredited by Oxford Brookes University as a 10 credit module at Level 7 (postgraduate level). However, charging for accreditation increases the administrative costs of running the MOOC. Drop out rates become more of a concern and there are cost implications for platform security, 'tracking' participants and working with unregistered participants. Quality assurance is a challenge' (Reilly \& Von Munkwitz-Smith, 2013).

Introducing MOOCs into the higher education curriculum also has implications for how teaching and scholarship are perceived and understood: 'Pedagogy itself is an implication of MOOCs' (Yuan \& Powell, 2013; Clar \& Barber, 2013). Increased participant numbers on an open online course or MOOC, the majority of whom are not registered for assessment or might not be formally registered at all, requires a change in approaches to teaching. The teacher can no longer have a one-to-one relationship with each participant. Some open online courses (such as EC\&1 831) call for voluntary mentors to support participants new to working in MOOCs, but this in turn has implications for the quality of critical feedback, as does peer assessment, which is how many xMOOCs have addressed this problem. In 2013 the FSLT MOOC, which was offered for credit, sought the help of FSLT12 alumni in supporting participants and providing feedback. The quality of this feedback has not yet been evaluated.

MOOC conveners may also need to rethink their pedagogical approach depending on the size and type of MOOC they are running. If learner autonomy is a key element of a MOOC environment, then this has implications for the design of tasks and expectations of completion, especially if those tasks are to be assessed. In addition, if the expectation is that MOOC participants will remix and repurpose information they find through their MOOC connections or on the Web, plagiarism and scholarly integrity may become a concern. Plagiarism was not an issue in FSLT12, but has been noted in some xMOOCs (Daniel, 2012).

MOOCs present institutions with political, economic, organizational, and, most importantly, pedagogical challenges. The pedagogical approach of the massive xMOOCs is currently under scrutiny since some research suggests that large-scale lectures and demonstrations do not support learner understanding (Mazur, 2012; Daniel, 2012). 
Small task-oriented cMOOCs, such as FSLT12, may be a better option for higher education institutions committed to opening their courses and promoting open academic practice. These institutions can blend well-established face-to-face courses with an open online course to build on and enhance their existing reputation and retain the uniqueness of their expertise.

As a small task-oriented MOOC, FSLT12 created the opportunities and means for more shared and more open engagement with thoughts in progress, right through to knowledge creation, within an emerging peer group. This exposed participants to the experience, and hopefully the benefits, of at least some aspects of open academic practice, and each participant was free to interpret this in his/ her own way.

Quality learning was thus achieved through a focus on academic identity and open academic practice; registration of a diverse mix of learners; optional assessment, which was designed to focus on remixing and repurposing thus encouraging commitment, innovation, and creativity; and learner autonomy, which allows for learners to determine their own learning paths and levels of engagement.

FSLT12 serves as an example of an emerging type of cMOOC, which one might call an open professional development MOOC.

It was illuminating and empowering at the same time to learn in such a clear way the value of CPD, reflection and what professionalism means. (follow up evaluation)

\section{Acknowledgement}

With thanks to Roy Williams, University of Portsmouth, for his helpful comments on this paper. 


\section{References}

Anderson, T. (2009). The dance of technology and pedagogy in self-paced instructions. AU Space. Retrieved from http:// hdl.handle.net/ 2149/2210

Anderson, T., \& Dron, J . (2011). Three generations of distance education pedagogy. IRRODL, 12(3). Retrieved from http:// www.irrodl.org/ index.php/irrodl/article/ view/ 890

Barnett, R. (2007). A will to learn: Being a student in an age of uncertainty. Open University Press.

Boxall, M. (2012). MOOCs: A massive opportunity for higher education, or digital hype? Higher Education Network. Retrieved from http:// www.guardian.co.uk/ higher-educationnetwork/blog/2012/aug/ 08/ mooc-coursera-higher-education-investment

Burton G. (2009). The open scholar. Retrieved from http:// www.academicevolution.com/2009/08/the-open-scholar.html

Clar, M., \& Barber, E. (2013). Learning online: Massive open online courses (MOOCs), connectivism and cultural psychology. Distance Education, 34(1), 129-136.

Clark, D. (2013). MOOCs: Taxonomy of 8 types of MOOC. Retrieved from http:// donaldclarkplanb.blogspot.ca/ 2013/04/ moocs-taxonomy-of-8-types-ofmooc.html

Conole, G. (2013). MOOCs as disruptive technologies: Strategies for enhancing the learner experience and quality of MOOCs. e-Lis. Retrieved from http:// eprints.rclis.org/ 19388/

Cormier, D. (2012). Embracing uncertainty and the strange problem of habituation. Retrieved from http:/ / davecormier.com/ edblog/ 2012/ 01/26/ embracinguncertainty-and-the-strange-problem-of-habituation/

Daniel, Sir J . (2012). Making sense of MOOCs: Musings in a maze of myth, paradox and possibility. J IME. Retrieved from: http:// wwwjime.open.ac.uk/jime/article/ viewArticle/ 2012-18/html

Downes, S. (2009). What connectivism is. Retrieved from http:// halfanhour.blogspot.co.uk/ 2007/ 02/ what-connectivism-is.html

Downes, S. (2009a). Connectivism dynamics in communities. Retrieved from http:// halfanhour.blogspot.com/2009/ 02/ connectivist-dynamics-incommunities.html 
Downes, S. (2009b). Access2OER: The CCK08 solution. Retrieved from http:// halfanhour.blogspot.co.uk/2009/02/access2oer-cck08-solution.html

Downes, S. (2013). The quality of massive open online courses. Retrieved from http:// mooc.efquel.org/ week-2-the-quality-of-massive-open-online-coursesby-stephen-downes/

Downes, S. (2013a). What the ' $x$ ' in 'xMOOC' stands for. Retrieved from https:// plus.google.com/ 109526159908242471749/ posts/LEwaKxL2MaM

Downes, S. (2013b). What makes a MOOC massive? Retrieved from http:// halfanhour.blogspot.co.uk/ 2013/01/ what-makes-mooc-massive.html

Downes, S. (2013c). The great rebranding. Retrieved from http:// halfanhour.blogspot.ca/2013/ 04/the-great-rebranding.html

Dron, J ., \&Anderson, T. (2009). Lost in social space: Information retrieval issues in Web 1.5. J ournal of Digital Information, 10(2).

Kop, R. (2011). The challenges to connectivist learning on open online networks: Learning experiences during a massive open online course. IRRODL, 12(3), 1938.

Kop, R., \& Bouchard, P. (2011). The role of adult educators in the age of social media. In M. Thomas (Ed.), Digital education: Opportunities for social collaboration (pp. 61-80). New York: Palgrave Macmillan.

Kop, R., \& Carroll, F. (2011). Cloud computing and creativity: Learning on a massive open online course. EURODL, 1- 11. Retrieved from http:// www.eurodl.org/ ?p=special\&sp=articles\&inum=2\&article=457

Kop, R., \& Fournier, H. (2011). New dimensions to self-directed learning in an open networked learning environment. International J ournal of Self-Directed Learning, 7(2).

Lane, L. (2012). Three kinds of MOOCs. Retrieved from http:/ lisahistory.net/ wordpress/ 2012/08/three-kinds-of-moocs/

Mackness, J ., Mak, S., Fai, J ohn, \&Williams, R. (2010). The ideals and reality of participating in a MOOC. Networked Learning Conference, Aarlborg. Retrieved from http:// www.lancs.ac.uk/ fss/ organisations/netlc/ past/nlc2010/abstracts/Mack $\underline{\text { ness.html }}$

Mazur, E. (2012). The scientific approach to teaching: Research as a basis for course design. Opening keynote presentation to ALT-C 2012 conference. 
Rees, J . (2013). The MOOC racket. Retrieved from http:// www.slate.com/articles/technology/future tense/2013/07/moocs_coul d be disastrous for_students and_professors.html

Reilly, M., \&Von Munkwitz-Smith, J . (2013). Helping to take the disruptive out of MOOCs. EDUCAUSE Review.

Roberts, G., Mackness, J ., Waite, M., \& Lovegrove, E. (2013). x v c: Hybrid learning in, through and about MOOCs. In Proceedings of OER13: Creating a Virtuous Circle. Nottingham, England. Retrieved from http://openbrookes.net/ firststeps12/research/dissemination/

Rodriguez, C. O. (2012). MOOCs and the AI-Stanford like courses: Two successful and distinct course formats for massive open online courses. Retrieved from http:// www.eurodl.org/materials/ contrib/2012/Rodriguez.pdf

Seely Brown, J ., \& Adler, R.P. (2008). Minds on fire: Open education, the long tail, and Learning 2.0. EDUCAUSE Review, 43(1), 16-32. Retrieved from http:// www.educause.edu/ero/article/minds-fire-open-education-long-tailand-learning-20

Siemens, G. (2004). Connectivism. A Learning theory for a digital age. Retrieved from http:// www.elearnspace.org/Articles/ connectivism.htm

Siemens, G. (2012a). What is the theory that underpins our moocs? Retrieved from http:/ / www.elearnspace.org/ blog/ 2012/ 06/ 03/ what-is-the-theory-thatunderpins-our-moocs/

Siemens, G. (2012b). MOOCs are really a platform. Retrieved from http:// www.elearnspace.org/ blog/2012/ 07/ 25/ moocs-are-really-a-platform/

Sloep, P. (2012). On two kinds of MOOCs. Retrieved from http:// pbsloep.blogspot.nl/2012/06/on-two-kinds-of-moocs.html

Tschofen, C., \& Mackness, J . (2012). Connectivism and dimensions of individual experience. IRRODL, 13(1). Retrieved from http:// www.irrodl.org/index.php/irrodl/article/view/ 1143

Waite, M., Mackness, J ., Roberts, G., \&Lovegrove, E. (2013, in press). Liminal participants \& skilled orienteers: A case study of learner participation in a MOOC for new lecturers. J OLT 
Watters, A. (2012). Dropping out of MOOCs. Is it really OK? Inside Higher Ed. Retrieved from http:// www.insidehighered.com/ blogs/hack-highereducation/dropping-out-moocs-it-really-okay

Weller, M. (2011). The digitalsScholar. How technology is transforming academic practice. Bloomsbury Academic.

Wenger, E. (1998). Communities of practice: Learning, meaning, and identity, Cambridge University Press, Cambridge.

Wenger, E. (2011). Learning in and across landscapes of practice. Presentation to Lancaster University Management School. Retrieved from http:// www.lancs.ac.uk/ celt/ celtweb/ ewenger

Williams, R., Mackness, J ., \&Gumtau, S. (2012). Footprints of emergence. IRRODL. Retrieved from: http:// www.irrodl.org/index.php/irrodl/article/ view/ 1267

Yuan, L., \& Powell, S. (2013). Moocs and open education: Implications for higher education. Cetis White Paper. Retrieved from http:// publications.cetis.ac.uk/2013/667

\section{Athabasca University $\mathbf{a}$}

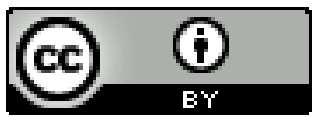

